\title{
Teoria Horizontalista da Moeda e do Crédito: Crítica da Crítica
}

\author{
Luiz Fernando Rodrigues de Paula
}

\author{
Professor Adjunto da Faculdade de Ciências \\ Econômicas da Universidade do Estado do Rio \\ de Janeiro (FCE/UERJ) e pesquisador do CNPq
}

\section{RESUMO}

Este artigo efetua, a partir de uma perspectiva pós-keynesiana, uma análise crítica do artigo "A teoria horizontalista da moeda e do crédito", de autoria de Saad-Filho e Lapavitsas. Para este propósito, o texto procura mostrar que embora estes autores avancem no entendimento de alguns aspectos importantes da dinâmica monetária e creditícia de economias capitalistas, algumas de suas críticas à teoria monetária pós-keynesiana revelam-se equivocadas no sentido de que estão baseadas num entendimento incompleto desta teoria. Ademais, a análise de Saad-Filho e Lapavitsas é por vezes ambígua, acabando por não definir um arcabouço teórico efetivamente alternativo à concepção neoclássica de moeda e crédito.

\section{PALAVRAS-CHAVE}

teoria pós-keynesiana, horizontalismo, oferta de moeda, crédito

ABSTRACT

This paper aims to develop a critical appraisal, from a Post Keynesian approach, of the paper "The horizontalist theory of money and credit", authored by Saad-Filho and Lapavitsas. For this purpose, the paper shows that although these authors highlight some

important features of the monetary and credit dynamic of capitalist economies, some of their criticism on the Post Keynesian monetary theory are misleading as they are based on an incomplete understanding of this theory. Furthermore, Saad-Filho and Lapavitsas' analysis is sometimes ambiguous, so that they are not able to define effectively an alternative approach to the neoclassical theory on money and credit.

KEY WORDS post Keynesian theory, horizontalism, money supply, credit

JEL Classification

$B O, E 4, E 5$ 


\section{INTRODUÇÃO}

Tem sido comum, entre autores marxistas brasileiros, a realização de críticas à teoria pós-keynesiana, em alguns casos procurando enfatizar diferenças metodológicas e conceituais entre as duas escolas (GERMER, 1996), em outros analisando a suposta insuficiência da teoria pós-keynesiana no tratamento de determinadas questões. (KLAGSBRUNN, 1996) Nesta última linha, alguns autores - ainda que com críticas a determinados aspectos da teoria pós-keynesiana - procuram buscar complementaridades entre estas duas abordagens, que tanto possa enriquecer o aparato teórico marxista quanto o pós-keynesiano. (MOLLO, 1997, 1998) Por sua vez, uma leitura pós-keynesiana da teoria monetária de Marx, procurando explorar similaridades com a teoria de Keynes e algumas insuficiências no tratamento de algumas questões teóricas na teoria monetária marxista é feita por Carvalho (1986).

Embora se reconheça que Marx e Keynes partam de construções teóricas muito distintas, em razão das questôes que cada um destes autores procurou responder, um traço comum no que tem sido assinalado no que se refere à teoria monetária heterodoxa - marxista ou pós-keynesiana - é a defesa de ambos ao "caráter não-neutro e endógeno da moeda que conduz à ruptura da igualdade entre gastos e receitas que sustenta a lei de Say" (MOLLO, 1998, p. 7), em oposição "à percepção do mundo econômico que tende ao equilibrio, concep̧̧ão fundamental da ortodoxia.” (Idem, p. 6) Conseqüentemente, tanto Marx como Keynes entenderam que "o dinheiro exerce papel fundamental" em economias capitalistas e recusaram, por isso, "a dicotomia [clássica] real x monetário.” (CARVALHO, 1986, p. 6)

Saad-Filho e Lapavitsas $(1999)^{1}$ retomam o debate entre as teorias marxista e pós-keynesiana, objetivando fazer uma crítica marxista à teoria póskeynesiana da moeda e do crédito. Embora os autores reconheçam a importância da teoria pós-keynesiana (ou, mais especificamente,

1 As citações do artigo de SAAD-FILHO \& LAPAVITSAS (1999), que se repetirão várias vezes ao longo do texto, serão acompanhadas, doravante, apenas do número da página do referido artigo. 
horizontalista) na sua oposição às análises convencionais, esta abordagem padeceria, segundo eles, de uma série de problemas relacionados principalmente à criação da moeda-crédito e no tratamento da inflação, e sugerem que "a melhor forma de resolver estes problemas, e desenvolver uma abordagem não-convencional consistente, é por meio do reforço dos elos entre a teoria da moeda e do crédito e a teoria da produção e circulação do capital.” (p. 24)

Portanto, as críticas feitas por Saad-Filho e Lapavitsas à teoria monetária pós-keynesiana parecem ir ao encontro daqueles autores marxistas que têm procurado mostrar a insuficiência da teoria pós-keynesiana no tratamento de determinadas questões, neste caso relacionado ao processo de criação da moeda-crédito em economias capitalistas. O presente artigo objetiva efetuar uma análise crítica do artigo de Saad-Filho e Lapavitsas, a partir de uma perspectiva pós-keynesiana estruturalista. Procura-se mostrar que, embora estes autores avancem no entendimento de alguns aspectos importantes da dinâmica monetária e creditícia de economias capitalistas, algumas de suas críticas à teoria pós-keynesiana revelam-se equivocadas no sentido de que estão baseadas num entendimento incompleto desta teoria. Ademais, a análise de Saad-Filho e Lapavitsas é por vezes ambígua, acabando por não definir um arcabouço teórico efetivamente alternativo à concepção neoclássica da moeda e crédito.

Mais especificamente, nossa crítica aos referidos autores está centrada nos seguintes aspectos:

- Saad-Filho e Lapavitsas parecem considerar a teoria horizontalista como a visão representativa dos pós-keynesianos, negligenciando o rico debate existente entre autores pós-keynesianos sobre a pertinência ou não da concepção horizontalista sobre a moeda e crédito, ${ }^{2}$ inclusive no Brasil - por exemplo, entre Costa $(1993,1994)$ e Carvalho (1993), e entre Ramalho (1995, 1997a e 1997b) e Paula (1996, 1997). ${ }^{3}$ Como o artigo, em determinado momento, se propõe a fazer

2 Só para citar alguns dos mais conhecidos textos, ver MOORE (1988A), GOODHART (1989) e POLLIN (1991).

3 Há, contudo, outros artigos que discutem a questão no Brasil, como, por exemplo, FREITAS (1999). 
uma "desconstrução de aspectos da teoria horizontalista (e, mais geralmente, pós-keynesiana)...” (p. 31, grifos acrescentados), é pertinente fazer uma leitura da crítica dos autores à luz de uma visão pós-keynesiana mais geral sobre moeda e crédito. Entendemos que o debate pós-keynesiano não se resume a uma discussão sobre a inclinação da curva de oferta de moeda, mas sim uma discussão bem mais complexa relacionada ao papel do banco central e dos bancos na dinâmica monetária de uma economia empresarial.

- Relacionado ao anterior, os autores ignoram contribuições importantes pós-keynesianas, em particular a hipótese de fragilidade financeira de Minsky. Isto os leva a fazer críticas à teoria póskeynesiana por vezes improcedentes, como no caso do papel do banco central no quadro de uma crise financeira.

- A análise dos autores é em vários momentos ambígua e mesmo contraditória, assumindo assunções da teoria convencional (por exemplo, teoria dos fundos de empréstimo) ou da teoria horizontalista, no qual se propõem criticar.

- Por fim, a abordagem dos autores parece carecer de um conhecimento mais aprofundado do "modus operandi" da política monetária, em particular do banco central e do sistema bancário. A nosso juízo, não é possível discutir a endogeneidade da oferta de moeda sem discutir a complexa relação entre banco central, bancos e agentes nãofinanceiros. Explicitamente os autores defendem a impossibilidade de uma teoria sobre a ação do banco central, e conseqüentemente de uma teoria de política monetária, e implicitamente não agregam uma teoria da firma bancária em sua análise.

Este artigo está dividido em cinco seções, além desta introdução. A seção 1 discute a visão horizontalista versus estruturalista a respeito da endogeneidade da oferta de moeda. A seção 2 analisa o papel da moeda na visão pós-keynesiana, enquanto a seção 3 examina a oferta de crédito e determinação da taxa de juros nesta perspectiva, sempre contrastando-a com a visão dos autores. A seção 4 discute a possibilidade de teorização da ação do banco central e também o papel do sistema financeiro no ciclo econômico. A última seção conclui o texto. 


\section{ENDOGENEIDADE DA OFERTA DE MOEDA: HORIZONTALISMO VERSUS ESTRUTURALISMO}

Nesta seção objetivamos apenas, de forma a "limpar inicialmente o terreno" para a discussão que se desenvolve a seguir, mostrar as diferenças fundamentais entre a concepção "horizontalista" e a "estruturalista" - para usar as expressões de Pollin (1991) - sobre a endogeneidade da oferta de moeda. O objetivo é mostrar que há diferenciações importantes entre estas concepções que não podem ser ignoradas.

O ponto de partida pós-keynesiano na discussão sobre a endogeneidade da oferta de moeda está relacionado a: (i) não aceitação de que a oferta de moeda é determinada exogenamente pelo banco central; (ii) a oferta de moeda, em economias com sistemas financeiros desenvolvidos, é determinada fundamentalmente pela expansão do crédito, sendo que o volume de crédito é dependente da sua demanda. A discussão pós-keynesiana refere-se ao grau e às causas da endogeneidade da oferta de moeda. Como uma primeira aproximação, na visão horizontalista entende-se que o banco central define apenas a taxa de juros de curto prazo, fornecendo fundos a essa taxa em quantidade ilimitada (portanto, a oferta de moeda é horizontal), o que é explicado pela necessidade do banco central fornecer reservas no montante correspondente à quantidade determinada pela demanda. Já na visão estruturalista (ou de endogeneidade parcial da oferta de moeda) a autoridade monetária não fornece fundos necessariamente sem limites e por isso a taxa de juros tende a subir quando a demanda por moeda cresce mais rapidamente do que oferta de reservas do banco central. Portanto, a oferta de moeda é influenciada pelas políticas do banco central e, deste modo, positivamente inclinada no plano moeda-juros. (FIOCCA, 2000, p. 79)

Sob o risco de simplificação, podemos resumir a visão horizontalista - que tem como base os trabalhos de Kaldor (1985) e Moore (1988b) - da seguinte forma:

- A criação da moeda resulta das necessidades de financiamento das firmas, famílias e governo. A causa fundamental do crescimento monetário é a decisão de gastos dos agentes. No caso das firmas, a 
criação de moeda-crédito permite que elas financiem seus gastos antes que o valor produzido seja realizado. A moeda-crédito é criada a partir decisóes tomadas pelos demandantes de crédito, atendidas pelos bancos.

- Moeda é derivada do crédito e determinada pela demanda, sendo criada como um subproduto dos empréstimos providos pelo setor bancário. Como não existe oferta de moeda independente da demanda, não pode haver um excesso de oferta de moeda. ${ }^{4}$

- Bancos comerciais nunca podem ser constrangidos em termos de suas reservas. Eles decidem a que taxa de juros estão dispostos a emprestar determinado montante, a partir de um mark-up sobre a taxa de captação. Eles expandem crédito, criando depósitos, e depois se preocupam com suas posições de liquidez. Conseqüentemente, a criação de moeda (depósitos) pelos bancos precede no tempo a criação de reservas. A elasticidade na concessão de crédito deriva da administração do passivo (devido à existência de um mercado secundário de reservas e o uso de gerenciamento de reservas por parte dos bancos) e da obtenção de recursos no banco central, o que lhes permite atender a toda a demanda por crédito existente à taxa de juros do mercado. Deste modo, os bancos são estabelecedores de preços e tomadores de quantidades.

- O banco central tem papel acomodatício, fornecendo as reservas requeridas pelos bancos, mesmo que seja a uma taxa de redesconto punitiva. Como emprestador de última instância ele zela pela saúde do sistema financeiro e, por isso, ele tende sempre acomodar as necessidades de reservas dos bancos quando estes dispõem de reservas insuficientes. Por isso, não existe nenhuma restrição quantitativa quanto às necessidades de reservas dos bancos.

4 MOORE (1989a, p. 11) sintetiza seu argumento da seguinte forma: "moeda é criada como um subproduto de novos empréstimos concedidos pelas instituiçôes depositárias. No mundo real, empréstimos criam depósitos. Ademais, mudanças nos empréstimos bancários são feitas por iniciativa dos tomadores de crédito e não pelos bancos. Bancos não podem esperar por excesso de reserva para fornecer novos empréstimos para o público. A ferta de moeda não aumenta por causa de injeções de reservas pelo banco central. Reservas são sempre obteniveis pela demanda, a algum preço. A oferta de moeda é endogenamente derivada do crédito e determinada pela demanda." 
- A taxa de juros é controlada pelo banco central, por meio de ajustamentos na taxa de redesconto ou na taxa de intervenção no mercado aberto. $\mathrm{O}$ banco central fixa o preço da oferta, mas não a oferta quantitativa de reservas. Tudo o que podem controlar é o custo dos banqueiros obterem reservas, ou seja, a taxa de juros.

Tal abordagem tem recebido críticas, que dizem respeito principalmente à exagerada passividade da política monetária e ao papel acomodatício do banco central, assim como ao comportamento passivo dos bancos em relação à demanda. ${ }^{5} \mathrm{~A}$ crítica central, com relação à postura acomodatícia do banco central, é que este pode, na realidade, se recusar a suprir reservas aos bancos a uma dada taxa de juros, não sancionando automaticamente as reservas adicionais demandadas pelos bancos às autoridades monetárias, ou simplesmente fazê-lo em condições punitivas que desestimule as instituições bancárias a concederem novos empréstimos. ${ }^{6} \mathrm{O}$ papel de emprestador de última instância do banco central na abordagem horizontalista seria exagerado no sentido de supor que qualquer aperto de liquidez dos bancos possa resultar numa ameaça à estabilidade do sistema, tendo em vista que o socorro financeiro do banco central ao sistema financeiro representa mais uma situação de anormalidade do que uma regra. Em outras palavras, um banco central que ofertasse reservas bancárias indiscriminadamente ao sistema acabaria por se constituir num fator de instabilidade econômica. Por outro lado, a aceitação da tese de que ao banco central é vedada qualquer pressão sobre o equilíbrio de reservas dos bancos implica que ele abra mão de mudanças nas taxas de juros. Assim, no modelo horizontalista desapareceria a política monetária. Outra crítica está relacionada ao papel passivo dos bancos em relação à demanda por crédito

5 A polêmica ao redor das teses horizontalistas de Basil Moore é encontrada em vários números da revista Journal of Post Keynesian Economics. A defesa destas teses é feita, por exemplo, em MOORE (1988a, 1989b), e as críticas por MEYLENDYKE (1988) e GOODHART (1989).

6 "[Moore] argumenta (...) que a demanda por crédito é uma variável não-discricionária e que isto implica que a oferta de moeda é derivada do crédito (pelos bancos). Este argumento só tem alguma validade quando visto em um horizonte de tempo de curto termo. Entretanto, bancos estabelecem parâmetros, na forma de taxas e condições, em que estenderão suas linhas de crédito, e eles podem alterálos caso entendam que estão concedendo um volume de empréstimos diferente do que eles gostariam." (MEULENDYKE, 1988, p. 396) 
na abordagem horizontalista, uma vez que as estratégias bancárias podem resultar na adoção de ações discricionárias no que tange ao crédito e, portanto, os bancos podem não compartilhar com os planos empresariais de um agente não-financeiro recusando-lhe a fornecer crédito, uma vez que os bancos, como qualquer outro agente, possuem preferência pela liquidez. ${ }^{7}$

Já a visão pós-keynesiana estruturalista, também conhecida por vezes como fundamentalista, ${ }^{8}$ pode ser resumida da seguinte forma:

- Atribui-se a endogeneidade da oferta de moeda à capacidade do sistema financeiro de aumentar o volume de empréstimos e de permitir a ampliação dos meios de pagamento acima do aumento de reservas.

- A expansão do crédito para atender a um maior volume de transações decorre do esforço do sistema bancário para contornar as limitações estabelecidas pela regulação do banco central, de modo a expandir suas atividades e elevar lucratividade. O sistema bancário tende a inovar de modo a expandir a oferta crédito em relação às exigências de reservas e aos parâmetros regulatórios do banco central.

- Os bancos, como qualquer firma, estão também sujeitos a incerteza, e, portanto, têm preferência pela liquidez. Suas decisões de portfólio são determinadas pelo trade-off rentabilidade e liquidez. Portanto, bancos, com preferência pela liquidez, poderão não acomodar passivamente a demanda por crédito, pois buscarão comparar os retornos esperados com os prêmios de liquidez de todos os ativos que podem ser comprados.

- Reconhece-se a capacidade do sistema bancário em acomodar a demanda por crédito, criando moeda bancária, mas não supõe que

7 Sobre este último aspecto, ver PAULA (1999) e FREITAS (1999).

8 Ver, por exemplo, MINSKY (1986), WRAY (1990, cap. 3 e 6), CARVALHO (1992, cap. 6) e DOW (1993). O que segue é apenas um breve resumo de alguns aspectos gerais da abordagem estruturalista. Reconhece-se, contudo, que há diferentes concepções sobre a problemática da moeda e do crédito entre os diversos autores pós-keynesianos. Para uma análise destas diferentes concepções, ver FIOCCA (2000, cap. 4). 
esta capacidade seja infindável nem que os bancos atendam plenamente à demanda por empréstimos.

- Bancos centrais têm meios de colocar alguma pressão quantitativa sobre os movimentos de expansão de moeda do sistema financeiro, ou seja, eles não são obrigados a acomodar toda a demanda de reservas dos bancos ou podem fazê-lo em condiçóes muito punitivas que forcem a redução na concessão de novos empréstimos.

- O banco central pode fazer alterações nos portfólios dos agentes via operaçóes de mercado aberto, substituindo moeda por títulos e viceversa. Assim, a demanda por moeda é influenciada pelas autoridades monetárias via alteraçóes nas taxas de juros de curto prazo. A concretização dos objetivos de política buscados pelas autoridades monetárias depende da reação dos bancos e suas políticas, podendo ser confirmada, atenuada ou contraposta por esta.

- A taxa de juros no mercado de varejo resulta da complexa interação entre as intervençóes de política monetária do banco central e as condições de mercado. Por isso, a curva de oferta de moeda é positivamente inclinada, mas não vertical (e nem horizontal).

Saad-Filho e Lapavitsas corretamente apontam algumas limitações na abordagem horizontalista, quando, por exemplo, sustentam que "o banco central pode afetar os termos e o preço nos quais o capital de empréstimo é transacionado no mercado monetário, afetando, assim, as taxas de juro em toda a economia" (p. 37), e reconhecem que "nem todos os pós-keynesianos admitem que a curva de oferta de moeda é horizontal." (p. 34) Contudo, acabam por concluir que: "A moeda-crédito é uma forma avançada de dinbeiro, criada principalmente como parte do passivo dos bancos e outras instituiçôes financeiras. Sua oferta é endógena num sentido mais profundo e complexo que a análise póskeynesiana pode conceber." (p. 42, grifos acrescentados) A visão dos autores é compatível com a teoria horizontalista-circuitista, pois moeda é vista como criada dentro do próprio processo produtivo, com o sistema bancário acomodando demanda por crédito e banco central fornecendo as reservas necessárias. Assim sendo, os autores parecem assumir uma visão próxi- 
ma da Banking School segundo a qual a moeda é criada de acordo com as necessidades de negócio da economia. Contudo, o papel do banco central e (principalmente) do sistema bancário é algo obscuro na análise dos autores, acabando por parecer ser a mesma "caixa preta" característica do modelo horizontalista. Nas próximas seções analisaremos com mais detalhes estas questôes.

\section{POR QUE A MOEDA IMPORTA PARA OS PÓS-KEYNESIANOS?}

Saad-Filho e Lapavitsas iniciam seu argumento afirmando que a moeda se "origina a partir do caráter essencial da mercadoria, que é de requisitar a troca com outra mercadoria com um valor de uso diferente." (p. 33), permitindo a superação da economia de escambo. A seguir, generalizam dizendo que "para a economia politica marxista, a moeda é inseparável das trocas", sendo ela compatível "com a idéia de que a moeda não é essencial para a reprodução da sociedade bumana." (p. 34, grifos acrescentados), para então criticar a teoria pós-keynesiana: "as explicações pós-keynesianas do porquê de as trocas mercantis serem necessariamente monetárias baseiam-se na presunção de que a moeda necessariamente media toda a atividade econômica. Isto embute a moeda na estrutura de toda sociedade humana, o que é ahistórico e falacioso. Teorias monetárias alternativas devem reconhecer que a existência (lógica e histórica) da moeda resulta da difusão das trocas, e que a moeda tem uma posição especial nas sociedades mercantis. A moeda pode ser usada como meio de troca, mas também como meio de pagamento, reserva de valor, e representante geral da riqueza." (p. 34) Ao final do artigo concluem que "É uma completa falácia fazer generalizaçôes a partir desta experiência limitada e atribuir à moeda um papel central na regulação das atividades econômicas. Não é impossível para as sociedades humanas se organizarem sem utilizar a moeda como reserva de valor e empregadora da capacidade humana para o trabalbo, mesmo se a moeda for utilizada como meio de troca." (p. 42, grifos acrescentados)

$\mathrm{O}$ argumento dos autores é ambíguo, pois não esclarecem claramente se a proposição acima vale para economias capitalistas. A afirmação dos autores - de que "a moeda não é essencial para a reprodução da sociedade humana" - 
obviamente pode ser verdadeira para algumas economias pré-capitalistas. Neste sentido, no que se refere a afirmativa de que "a existência (lógica e histórica) da moeda resulta da difusão das trocas, e que a moeda tem uma posição especial nas sociedades mercantis", como bem desenvolveu Marx em sua análise do capital, não temos nada a discordar. Portanto, a crítica feita à teoria pós-keynesiana sobre a falácia de se fazer generalizações a respeito de uma experiência limitada parece-nos sem sentido já que está claro que o que se está sendo teorizando é a respeito de uma economia capitalista com um sistema monetário e creditício desenvolvido. Nesta, a moeda desempenha um papel crucial, pois "afeta motivos e decisóes dos agentes." $\mathrm{De}$ fato, a moeda - para Keynes e pós-keynesianos - é vista como uma representação geral da riqueza, um ativo que pode ser retido como poder de compra em sua forma mais pura, a ser gasto em alguma data futura indefinida. Por seu atributo de liquidez por excelência, ${ }^{10}$ ela afeta as escolhas que são feitas com relação à alocação da riqueza, devido à sua capacidade de liquidar dívidas e representar o poder de compra em sua forma mais pura ${ }^{11}$ (voltamos ao assunto abaixo).

9 É conhecida a citação de KEYNES (1973a, p. 408-9) em que ele define a economia monetária como aquela em que a moeda, ao invés de ser uma mera conveniência temporária, "joga papel próprio e afeta motivos e decisões e é, em resumo, um dos fatores operativos na situação, de modo que o curso dos eventos não pode ser predito, seja no longo como no curto periodo, sem um conhecimento do comportamento da moeda entre o primeiro e o último estado."

10 Liquidez depende das características do mercado onde um dado ativo é transacionado. Quanto mais "eficiente" este mercado, mais líquido o ativo se torna porque mais seguro ele se torna aos olhos dos donos da riqueza. (CARVALHO, 1992, cap. 5) Este argumento é desenvolvido por DAVIDSON (1992, p. 46, grifos acrescentados) que diz: "O grau de liquidez depende do grau de organização de um mercado spot relevante. Dependendo das práticas sociais e instituições, ograu de liquidez de qualquer ativo pode mudar de tempo em tempo uma vez que as regras para qualquer ativo no mercado spot se alterem. Diferenças no grau de liquidez entre ativos refletem diferenças nos custos de transação e na rigidez do preço à vista ao longo do tempo. Quanto menor os custos de transação e/ou maior a rigidez, maior o grau de liquidez de qualquer ativo.” Fica claro nesta citação que a liquidez é um atributo institucional de mercado.

11 Conseqüentemente, a não-neutralidade no longo período, proposta por Keynes, repousa na proposição de que a moeda e ativos não-reprodutíveis são formas alternativas de acumulação de riqueza e que, portanto, o agente reter moeda (e outros ativos líquidos) como um ativo, em momento de maior incerteza, pode ser um ato racional. 
Para os autores pós-keynesianos, ao contrário do que sugerem Saad-Filho e Lapavitsas, é fundamental levar em conta o quadro histórico-institucional na análise da dinâmica monetária de uma economia. Victoria Chick (1992), por exemplo, mostra como a moeda e o crédito evoluíram em uma sociedade capitalista. Chick apresenta vários estágios de evolução do sistema bancário, desde a fase primitiva dos bancos, em que estes eram numerosos e pequenos, além de semi-isolados geograficamente, até a fase mais recente da evolução bancária, que pressupõe a existência de um banco central em sua função de emprestador de última instância do sistema bancário e o desenvolvimento de técnicas de administração do passivo por parte dos bancos, deixando os depósitos de serem uma conseqüência passiva da política de empréstimos dos bancos. ${ }^{12}$ Acrescente-se, ainda, a importância do tempo histórico na irreversibilidade dos fenômenos e decisões dos agentes, de acordo a concepção de Keynes e autores pós-keynesiano, dado que o tempo é unidirecional, fluindo do passado para o futuro e não reversível como na teoria clássica. Deste modo, não há uma reversão de planos e processos sem custos em uma economia monetária. (CARVALHO, 1992, cap. 3)

Saad-Filho e Lapavitsas afirmam, ainda, com relação ao conceito de incerteza não-probabilística, tão caro aos pós-keynesianos, que é "errado conchir que a forma mais racional de se conviver com [irreversibilidade do tempo e a incerteza] é mediante contratos monetários. Todas as sociedades têm leis, hierarquias, costumes e crenças religiosas que reduzem a incerteza a respeito do futuro, e contribuem para a reprodução econômica do grupo, apesar da constante luta contra as forças da natureza" (...) "A presunção de que a moeda é a melhor (ou, pior ainda, a unica) forma de se reduzir a incerteza é um exagero sem qualquer base histórica." (p. 32) Ora, a existência de contratos monetários é uma característica de uma economia monetária ou capitalista, que viabiliza a interação material entre os agentes, do qual a estabilidade do valor da moeda enquanto unidade de conta para a realização de contratos é fundamental para que os agentes aceitem compromissos contratuais, ${ }^{13}$ tal como

12 Para uma outra abordagem sobre a evolução histórica dos bancos, ver KREGEL (1997). 
apontado por Davidson (1994); portanto, é historicamente determinada. Keynes não desconhecia absolutamente que leis, hierarquias, costumes e crenças fossem redutores de incerteza quanto ao futuro. Assim, a afirmativa de que a moeda para os pós-keynesianos é a melhor e única forma de reduzir a incerteza parece-nos equivocada. De fato, para Keynes, a existência de convenções (que inclui de forma importante, mas não exclusivamente, os contratos monetários) reduz a incerteza, mas não acaba com ela. Em um mundo em que as expectativas dos agentes econômicos são construídas sob condições de incerteza, e as ações no presente são feitas sob a dupla pressão de um passado irrevogável e um futuro desconhecido, tais expectativas são sujeitas a desapontamento e intrinsecamente instáveis, devido à possibilidade de uma contínua alteração no estado de confiança dos agentes. O estado de confiança expressa o grau limitado de certeza sobre a ocorrência de um determinado evento e é, portanto, inversamente proporcional à incerteza presente nas expectativas formuladas pelos agentes. Estes, em suas decisões relativas à valorização de sua riqueza, procuram tomar decisões seguras que minimizem a incerteza, por meio de normas de comportamento convencionais, que leve em conta não só o estado vigente de opinião sobre o futuro como também a opinião da maioria ou da média dos participantes do mercado. (KEYNES, 1973b) Os agentes buscam, assim, criar regras, convenções, rotinas e práticas que, ao invés de eliminar, permitam "contornar" a incerteza de suas expectativas quanto ao futuro. ${ }^{14}$ Neste sentido, como destacam Ferrari Filho e Conceição (2001, p. 7), “a idéia de 'socialização do investimento' [de Keynes] pode estar relacionada aos mecanismos institucionais endógenos criados pela sociedade para que as tomadas de decisões dos individuos sejam realizadas de maneira menos adversa possivel."

13 Portanto, a afirmação de Saad-Filho e Lapavitsas de que: "Para Davidson ... a melhor forma de se ligar o passado inalterável ao futuro desconhecido é via contratos monetários. Isso implica que a mais importante função da moeda é a de reserva de valor" (p. 31, itálicos negritos acrescentados), provavelmente se deve a um descuido na redação do texto.

14 Para uma análise sobre os critérios racionais de tomada de decisões sob incerteza, a partir da análise de Keynes, ver POSSAS (1993). 
Por fim, os autores acrescentam que: "Além disso, a abordagem pós-keynesiana não reconhece que a moeda pode aumentar a incerteza em torno das atividades econômicas (...) A incerteza torna-se ainda maior quando se inicia o comércio da moeda e de instrumentos financeiros derivados da moeda." (p. 32, grifos no original) De fato, o aspecto distintivo da teoria pós-keynesiana da moeda é a importância atribuída à incerteza com relação ao futuro na determinação do comportamento dos agentes. Incerteza não-probabilística refere-se a fenômenos para os quais "não existe base cientifica para o qual formar cálculos probabilísticos", pois o conjunto de premissas necessárias para formar uma função de probabilidade pode não ser conhecido. ${ }^{15}$ Logo, as decisões dos agentes, que têm que ser feitas no presente, referem-se a um futuro inerentemente incerto, já que as informações existentes são necessariamente insuficientes; por isso, tornam-se basicamente especulativas. Em um mundo não-ergódico, a existência incontornável da incerteza no tempo real (histórico) impede que os agentes possam projetar eventos passados para o futuro e, conseqüentemente, a constituição de distribuições de probabilidades que fundamentem a formulação de expectativas racionais por parte dos agentes sobre os acontecimentos futuros. (DAVIDSON, 1994)

$\mathrm{Na}$ abordagem pós-keyenesiana a relação entre moeda e incerteza é - a princípio - inversa à estabelecida pelos autores, no sentido de que é a existência da incerteza que faz com que os agentes demandem moeda por outros motivos (precaucional, especulativo) que não seja só de transação. A moeda - como já assinalado - é um ativo demandado quando a incerteza aumenta pelos atributos específicos de liquidez absoluta. É a incerteza quanto ao futuro que faz com que o público possa decidir reter sua riqueza na forma de moeda (ou outros ativos com alta liquidez) ao invés de ativos produtíveis por trabalho, no que pode resultar na redução no nível de produção e aumento do desemprego dos trabalhadores. Porém, a relação entre

15 Em diferentes trabalhos, Keynes distinguiu incerteza de eventos prováveis, especialmente em relação a decisões envolvendo a acumulação de riqueza e preferência pela liquidez. Por incerteza, ele entendia que "decisões humanas afetando o futuro, seja pessoal, politico ou econômico, não podem depender de expectativas estritamente matemáticas, uma vez que a base para fazer tais cálculos não existe" (KEYNES, 1964, p. 162-3), o que significa, portanto, que "não existe uma base cientifica para o qual se possa formar qualquer cálculo probabilístico. Nós simplesmente não sabemos.” (KEYNES, 1973 b, p. 114) 
moeda e incerteza também pode ocorrer da forma estabelecida pelos autores, ou seja, de que "a moeda pode aumentar a incerteza em torno das atividades econômicas." (p. 32) Carvalho (1992, p. 41, grifos acrescentados) coloca claramente este ponto: "Por causa da (ou, nesta parte do argumento, relacionada a) moeda nós teremos incertezas de mercado permeando a atividade econômica. Incerteza é parcialmente um axioma, mas também parcialmente uma conseqüência da natureza dos arranjos monetários modernos." Por exemplo, a instabilidade do valor da moeda em condições de inflação elevada na sua função de unidade de conta de contratos - pode ser o elemento instabilizador na economia, causando um aumento na incerteza da atividade econômica, podendo inclusive provocar uma ruptura no sistema de contratos nominais.

Acrescente-se, ainda, que Keynes, no capítulo 12 da Teoria Geral, ressaltou que os processos especulativos nos mercados financeiros podem ser disruptivos e, neste sentido, podem aumentar a incerteza que permeia os negócios na economia. Keynes e pós-keynesianos sustentam que há fortes conexões entre os setores financeiro e real da economia. Uma dessas conexões é o impacto da atividade especulativa sobre a atividade produtiva, especialmente sobre o investimento. É bem conhecida a passagem da Teoria Geral em que Keynes (1964, p. 159) diz que "a posição é séria quando o empreendimento torna-se uma bolha sob um redemoinho da especulação. Quando o desenvolvimento do capital de um pais torna-se um subproduto das atividades de um cassino, o trabalbo será provavelmente mal feito." De fato, um dos aspectos que os economistas pós-keynesianos têm destacado - como Minsky e Davidson - é a conexão entre o lado real e lado financeiro da economia via mercado financeiro, mostrando que o sistema financeiro tem um papel dúbio nas economias capitalistas, pois ao mesmo tempo que podem potencializar o processo de acumulação, podem também ter caráter instabilizante, com efeitos negativos sobre as variáveis reais da economia (produto e emprego). ${ }^{16}$

16 Para um aprofundamento desta questão, ver ALVES JR. et al (1999/2000). 


\section{OFERTA DE CRÉDITO E DETERMINAÇÃO DA TAXA DE JUROS}

Saad-Filho e Lapavitsas analisam na seção 4.2 de seu artigo a oferta de moeda e o papel do banco central (este segundo aspecto será examinado com detalhes na seção seguinte deste artigo). Segundo eles: " $A$ oferta de capital de empréstimo pelos bancos e outras instituições financeiras tem uma base objetiva na rotação do capital social, e é geralmente independente da preferência pela liquidez.” (p. 35) Durante a rotação, o capital cria temporariamente fundos ociosos que "tendem a ser mantidos como depósitos bancários, e constituem a base das reservas do sistema bancário. Ao serem reciclados pelo sistema bancário, eles podem estimular a geração de mais-valia adicional em outros pontos da economia. A criação regular de moeda ociosa durante a reprodução econômica é o fundamento do sistema de crédito capitalista. De forma geral, o sistema de crédito é um mecanismo para a realocação de fundos ociosos entre capitais industriais e comerciais, aumentando a eficiência do processo de acumulação de capital.” (p. 36, grifos no original) Mais à frente afirmam que: "Existe uma âncora nominal para o valor da moeda. Esta âncora opera por meio da necessidade de os bancos manterem reservas adequadas, restringindo a possibilidade de estes criarem moeda-crédito." (p.40) E concluem que: "Neste nivel de análise, não bá necessidade nem espaço para a intervenção do banco central na determinação da taxa de juros: ela reflete a oferta e demanda por capital de empréstimo." (p. 36, grifos acrescentados)

Analisemos com cuidado os argumentos desenvolvidos por Saad-Filho e Lapavitsas. Comecemos pela afirmação de que "a oferta de empréstimo é geralmente independente da preferência pela liquidez." $17 \mathrm{Na}$ visão póskeynesiana os bancos são em boa medida (mas não totalmente) responsivos à demanda por crédito, por meio do que Minsky (1986, cap. 10) chamou de "administração dinâmica do balanço", ou seja, usando técnicas de admi-

17 Portanto, Saad-Filho e Lapavitsas, apesar de críticos do horizontalismo, acabam por reproduzir um dos problemas desta concepção, ao não perceberem a importância da preferência pela liquidez dos bancos na dinâmica monetário-financeira de uma economia capitalista. 
nistração de passivo, fazendo gerenciamento de reservas e lançando inovações financeiras de modo a alavancar suas operações ativas, quando isto for lucrativo a eles (voltaremos a este ponto adiante). Todavia, com já assinalamos anteriormente, na perspectiva pós-keynesiana estruturalista, os bancos têm um grau de discricionariedade na concessão do crédito, pois na administração de seu portfólio se defrontam com o trade-off liquidez e rentabilidade. Bancos, como qualquer agente que atua sob condiçóes de incerteza, têm preferência pela liquidez e isto tem impacto nas suas decisões de crédito. A sua escala de preferência pela liquidez expressa a precaução que é inerente aos resultados incertos da atividade bancária, no que se refere ao retorno de suas aplicações. Neste sentido, a estratégia dos bancos é definida de acordo com as suas percepções de risco e oportunidades de lucro. Bancos, com preferência pela liquidez, poderão não acomodar passivamente a demanda por crédito, pois buscarão comparar os retornos esperados com os prêmios de liquidez de todos os ativos que podem ser comprados. Isto significa que a disponibilidade de crédito poderá diminuir devido à maior preferência pela liquidez, sem estar relacionada diretamente aos riscos inerentes aos empréstimos, fazendo com que o racionamento de crédito possa surgir quase que independentemente dos retornos esperados dos projetos de investimento. (DOW, 1996) Portanto, é fundamental levar em conta as "preferências" dos bancos ao se analisar a dinâmica monetáriofinanceira de uma economia capitalista.

Quanto ao argumento de que os fundos ociosos são reciclados pelo sistema bancário, constituindo a base de reserva dos bancos, os autores parecem estar implicitamente incorporando em sua análise o multiplicador bancário, ${ }^{18}$ adotando, assim, aquilo que James Tobin (1987) - em texto originalmente publicado em 1963 - chamou de "visão velha" dos bancos. Nesta visão, os bancos funcionam como "máquinas de fazer dinheiro", a serem acionados pelas autoridades monetárias, sendo a firma bancária uma insti-

18 O pressuposto do multiplicador bancário é que o banco individual pode aumentar seus empréstimos somente depois que os depositantes tenham aumentado seus saldos nele, de modo que o banco tenha excesso de reservas em caixa para emprestar. 
tuição passiva que busca maximizar seus lucros por meio da expansão de empréstimos, restringida pelos requerimentos legais de reserva (variável controlada pela autoridade monetária). Da mesma forma que na visão velha, o banco, na análise de Saad-Filho e Lapavitsas, parece ser um agente passivo, criador "quase-técnico" de moeda, estabelecida previamente a partir de uma certa disponibilidade de reservas. Em outras palavras, os bancos são restringidos por reservas, sendo a criação de moeda-crédito feita a la multiplicador bancário.

Na perspectiva pós-keynesiana, de forma distinta da visão convencional de firma bancária, os bancos são vistos como agentes ativos que administram dinamicamente os dois lados de seu balanço, o que significa que eles não tomam o seu passivo como dado, na medida em que procuram influenciar as preferências dos depositantes, por meio do gerenciamento das obrigações e da introdução de inovações financeiras. ${ }^{19}$ Assim, as instituições bancárias modernas procuram agir, do lado das obrigações, de forma dinâmica, adotando uma atitude ativa na busca de novos depósitos ou mediante a administração das necessidades de reservas, o que faz com que os fundos que financiam os seus ativos sejam fortemente condicionados pelo próprio comportamento do banco. Portanto, mais do que receber passivamente os recursos de acordo com as escolhas realizadas pelo público, os bancos procuram interferir nessas escolhas das mais diferenciadas formas, promovendo alterações em suas obrigações para que possam aproveitar-se de possíveis oportunidades de lucro. Deste modo, nesta perspectiva, a dinâmica dos bancos afeta de forma decisiva as condições e volume de financiamento da economia e, conseqüentemente, as decisões de gasto dos agentes. ${ }^{20}$

Por fim, quanto à afirmação (derivada da exposição anterior) de que "[a taxa de juros] reflete a oferta e demanda por capital de empréstimo” (p. 36), e de que "existe uma áncora nominal para o valor da moeda [que] opera por meio da necessidade de os bancos manterem reservas adequadas, restringindo a possibi-

19 Ver, neste particular, MINSKY (1986, cap. 10).

20 Para um aprofundamento da dinâmica dos bancos em economias monetárias, ver PAULA (1999). 
lidade de estes criarem moeda-crédito" (p. 40), os autores parecerem assumir implicitamente, na explicação de determinação da taxa de juros, uma posição semelhante à da teoria de fundos de empréstimo, ${ }^{21}$ no sentido de que a taxa de juros não é um fenômeno monetário mas um fenômeno real determinado no mercado de bens (ainda que desenvolvam uma outra linha de argumentação em relação à teoria dos fundos de empréstimos). Para Keynes (1964), contudo, a taxa de juros é definida como uma recompensa para abrir-se mão da liquidez e, assim, da riqueza na forma monetária, uma vez que a moeda é o ativo com o maior prêmio de liquidez dentre todos os ativos. Em outras palavras, é o "preço" mediante o qual o desejo de manter a riqueza em forma líquida se concilia com a quantidade de moeda disponível. A taxa de juros, portanto, ao invés de ser a recompensa pela "espera", pelo adiamento do consumo, é, segundo Keynes, a recompensa por não entesourar. Neste sentido, a taxa de juros é um fenômeno eminentemente monetário - determinado pela preferência pela liquidez dos agentes e pela política das autoridades monetárias (enquanto gestoras da política monetária) - e não enraizada a fatores reais (tais como preferências intertemporais dos agentes e produtividade do capital), como estabelecia a teoria clássica.

\section{PAPEL DO BANCO CENTRAL E DO SISTEMA FINANCEIRO NO CICLO ECONÔMICO}

Nesta seção discutimos o papel do banco central na dinâmica monetária e sua relação com o sistema financeiro, inclusive em momentos de crise financeira. Para Saad-Filho e Lapavitsas: "não pode haver uma teoria abstrata da capacidade de o banco central influenciar as taxas de juros", pois isto "depende da estrutura institucional do sistema monetário e creditício, e da maneira

21 Para a teoria de fundos de empréstimo, a taxa de juros é o "preço" que equilibra a demanda por recursos para investir (determinada pela produtividade potencial do investimento) e a propensão de abster-se do consumo imediato. Em outras palavras, a taxa de juros seria o fator equilibrante que determina a igualdade entre a demanda de poupança, resultante do investimento novo que pode ser realizado a determinada taxa de juros, e a oferta de poupança, estabelecida a partir da propensão da comunidade a poupar. 
segundo a qual as pressões econômicas são retratadas por meio daquela estrutura institucional." (p. 37) A incapacidade de o banco central influenciar a taxa de juros é mostrada levando-se em conta três fatores: (i) a possibilidade do passivo monetário do banco central ser convertido num ativo de reserva (divisas internacionais), como, por exemplo, no caso do banco central ser confrontado com uma rápida perda de reservas, por causa de um colapso na confiança do sistema bancário, sendo ele obrigado a elevar a taxa de juros para defender suas reservas; (ii) no caso deste passivo monetário não ser diretamente conversível num ativo de reserva, sua incapacidade de influenciar as taxas de juros é limitada pela posição do balanço de pagamentos; (iii) por fim, a possibilidade de crise econômica e financeira, intrínseca ao capitalismo, também limita a capacidade do banco central influenciar a taxa de juros, já que numa crise financeira o banco central é confrontado com a necessidade de oferecer liquidez ao sistema financeiro para evitar a possibilidade de falências resultantes da incapacidade de pagamento. Contraditoriamente, os autores argumentam a seguir que "defender suas reservas de ativos é prioritário para o banco central. Isto leva ao aumento da taxa de desconto durante a crise, e à recusa de acomodar os pedidos desesperados de liquidez dos bancos" (p. 38), concluindo ainda que "mesmo se alguns bancos ou companhias falirem, o sistema financeiro como um todo não tem que entrar em colapso.” (p. 39)

Nossa crítica à análise dos autores com relação ao papel do banco central está relacionada aos seguintes aspectos. Na visão dos autores, como visto, não há uma teoria geral das políticas do banco central e tampouco uma teoria para a política monetária, o que implicitamente parece resultar no fato de que as autoridades monetárias atuam a reboque do sistema bancário. Como resultado, a sua principal função seria a de emprestador de última instância do sistema, sobretudo em momentos de crise financeira, ainda que contraditoriamente os autores critiquem os pós-keynesianos horizontalistas, colocando que estes "subestimam a capacidade do banco central restringir quantitativamente seu passivo." (p. 39) Neste particular, parece-nos que o argumento desenvolvido sobre a impossibilidade de haver uma teoria do banco central não está muito claro. Vejamos a questão. 
Na questão levantada pelos autores relacionada ao exercício de política monetária de acordo com o regime cambial adotado por um país, eles parecem não considerar - antes de qualquer coisa - que o banco central pode esterilizar ou injetar reservas no mercado, "neutralizando", ao menos parcialmente, os impactos de uma expansão ou contração da base monetária sobre a taxa de juros, de acordo com os seus objetivos e metas de política monetária. Evidentemente, isto não quer dizer que não haja uma crescente dificuldade de exercício de políticas macroeconômicas em economias com conta de capital aberta devido à intensa mobilidade no movimento de capitais, mesmo no caso de países hegemônicos com moeda forte, como é o caso dos Estados Unidos. De fato, há vários estudos que têm apontado uma crescente complexidade na relação entre juros-câmbio em economias globalizadas, de acordo com o regime cambial adotado. Mostram ainda que não há nenhum regime cambial "ótimo", devendo-se inclusive considerar, para a escolha do mais adequado regime, as particularidades de cada país. ${ }^{22}$

É fundamental separar dois aspectos - de certa forma diferenciados - na atuação do banco central: um aspecto é que ele como gestor de política monetária deve atuar no sentido de procurar dar estabilidade ao mercado monetário-financeiro, evitando, por exemplo, oscilações bruscas na taxa de juros que poderiam afetar negativamente as expectativas dos agentes e, ao mesmo tempo, deve adotar políticas monetárias ativas visando atingir suas metas de mais longo prazo, como inflação, nível de produto e emprego etc. Este aspecto está relacionado, em primeiro lugar, ao gerenciamento diário da liquidez, por meio do qual o banco central procura contrabalançar os movimentos de liquidez decorrentes das variaçóes autônomas das reservas bancárias, visando basicamente neutralizar as oscilações da taxa de juros básica de curto prazo decorrentes destas variaçóes autônomas; em segundo lugar, diz respeito à sinalização do rumo da política monetária ao sistema financeiro, em que o banco central procura influenciar a estrutura de taxa de juros da economia por intermédio da variável operacional bási-

22 Ver, por exemplo, FRANKEL (1999). 
ca, ou seja, da taxa de juros de curto prazo, com a finalidade de atingir objetivos mais amplos de política monetária, relacionados a uma estratégia de mais longo prazo. ${ }^{23}$ Neste particular, a visão pós-keynesiana e mesmo de alguns autores keynesianos convencionais, como James Tobin, é que a política monetária, atuando na composição do portfólio dos agentes, é potente para impactar, de forma permanente, as variáveis reais da economia, ao induzir a troca de rendimentos de juros por lucros recompensadores relacionados, por exemplo, à aquisição e uso de bens de capital. ${ }^{24}$

Um segundo aspecto da atuação do banco central, distinto do primeiro, é que ele, na sua função de zelar pela saúde do sistema financeiro, deve atuar como emprestador de última instância do sistema em momentos de perigo de crise bancária, utilizando inclusive operações de socorro, de modo a evitar que a crise resulte numa crise sistêmica. Não se trata, contudo, de uma função corriqueira, de ação diária no mercado financeiro. Ainda assim, esta função é cara para os pós-keynesianos, para quem, entretanto, prevenção à crise ao invés de socorro à crise - deve ser o objetivo de política. (DAVIDSON, 1999) Acrescente-se que, ao contrário do que afirmam os autores de que "se alguns bancos (... falirem o sistema financeiro como um todo não tem por que entrar em colapso", o perigo de que uma crise de confiança acarrete uma crise sistêmica é algo factível, pois o sistema bancário depende crucialmente da confiança de seus clientes. Os bancos não são um agente qualquer, pois eles são ao mesmo tempo criadores de moeda e operacionalizadores do sistema de pagamentos da economia. Há várias evidências empíricas mostrando os enormes custos causados a uma economia por uma crise bancária. ${ }^{25}$

23 Para uma análise sobre a operacionalidade da política monetária, ver TORRES (1999).

24 Para uma análise mais detalhada sobre a política monetária sugerida por Keynes e autores póskeynesianos, ver SICSÚ (1999).

25 Para uma análise das implicações das falências bancárias, ver KAUFMAN (1996), para quem o que torna "a percepção das falências bancárias mais importante, particularmente para a política pública, é que a falência pode contaminar outros bancos e possivelmente mesmo além do sistema bancário para o sistema financeiro como um todo. Receios similares não são geralmente percebidos em relação à falência de outras firmas." (p. 4) 
Por último, a crítica feita por Saad-Filho e Lapavitsas sobre as crises financeiras, cujas "explicações geralmente não partem de uma análise das causas sistemáticas da crise", parece negligenciar a rica contribuição de Hyman Minsky, um dos mais renomados autores pós-keynesianos. O papel do banco central e dos bancos no ciclo econômico foi analisado teoricamente por Minsky no desenvolvimento de sua conhecida hipótese de fragilidade financeira. Minsky $(1982,1986)$ argumenta que o modo por meio do qual as firmas financiam a aquisição de bens de capital no sistema bancário é responsável pelo comportamento cíclico da economia capitalista. Para ele, a decisão de investimento, de escolha de ativos, é concomitante à escolha de meios de financiamento, sendo que a combinação entre ambas as decisões definem o grau de vulnerabilidade da economia a mudanças adversas na conjuntura econômica. De acordo com sua hipótese da fragilidade financeira, a própria dinâmica do processo de crescimento econômico leva as firmas a se tornarem crescentemente endividadas para expandir o investimento. As flutuações cíclicas da economia resultam da maneira como as firmas financiam suas posiçóes de carteira, com a fragilidade se elevando em períodos de crescimento devido ao aumento do número de agentes com posturas especulativas. ${ }^{26}$ Deste modo, como assinalam Dymski e Pollin (1992, p. 40): "Minsky argumenta que existe uma tendência inerente das estruturas financeiras capitalistas se moverem de estado de robustez para estado de fragilidade ao longo do tempo. Isto é devido a mudanças nas expectativas que ocorrem no curso do ciclo de negócios, e a forma em que este mudança é transmitida através do sistema financeiro." Os bancos, em particular, têm um papel importante e contraditório no ciclo de Minsky, uma vez que seu comportamento, ao mesmo tempo que é capaz de amplificar o crescimento econômico na fase expansionista do ciclo, devido a sua capacidade de acomodar a demanda por crédito das firmas, durante a fase descendente pode amplificar a desaceleração econômica, uma vez que as estratégias defensivas adotadas pelos bancos, em face de sua maior preferência pela liquidez, re-

26 Unidades especulativas são aquelas que especulam que não vai haver aumento nos custos financeiros a ponto de inviabilizar seus projetos e, por isso, nos períodos iniciais, seus lucros esperados não são suficientes para pagar o total do principal da dívida, ou seja, os compromissos de pagamento em dinheiro referentes a dívidas que excedem a renda bruta esperada, pois espera-se que nos períodos seguintes os agentes obtenham um excesso de receita que compense as situações iniciais de déficit. Por isso, tais unidades necessitam de refinanciamento de parte das obrigaçôes. 
sultam em um racionamento do crédito que acaba por inviabilizar a rolagem da dívida por parte das empresas não-financeiras. ${ }^{27} \mathrm{~A}$ ação do banco central - de prover a economia com adequada liquidez durante a crise - é tida como fundamental para evitar ou mitigar a crise, pois, na ausência de um emprestador de última instância, a propagação do pânico pode levar à ruptura do sistema de pagamentos e à corrida bancária.

\section{CONCLUSÃO}

Saad-Filho e Lapavitsas concluem afirmando que "o progresso desta teoria [pós-keynesiana] depende de uma explicação convincente e historicamente relevante da moeda e do crédito capitalistas, suas relaçôes complexas com os circuitos de produção e circulação, e a instabilidade que permeia a acumulação de capital.” (p. 43) Se as críticas feitas neste artigo a Saad-Filho e Lapavitsas são consistentes, o que parece resultar do trabalho desses autores é uma contribuição ambígua, não definindo um arcabouço teórico efetivamente alternativo à teoria neoclássica da moeda e crédito. A moeda e o crédito na abordagem dos autores parecem não desempenhar um papel fundamental na dinâmica das economias capitalistas.

A construção de um aparato teórico alternativo requer uma teoria que seja consistente teoricamente e, ao mesmo tempo, seja capaz de dar uma explicação convincente acerca da complexidade do "mundo real" que vivemos. Um arcabouço teórico heterodoxo, alternativo à teoria neoclássica, deve rejeitar a lei de Say (e suas variantes, como a teoria dos fundos de empréstimo), e as noções de harmonia, estabilidade e equilíbrio a ela relacionada já que a moeda não é um instrumento transitório e neutro em seu efeito, mas um elemento que pode ser instabilizador da atividade econômica -, abandonando assim o estudo das condições estritamente controladas das situações de equilíbrio. Ademais, deve ser consistente com a concepção de não-neutralidade da moeda, seja no curto ou no longo período, e de

27 Para uma análise do papel dos bancos no ciclo de Minsky, ver PAULA \& ALVES JR. (2003). 
endogeneidade (parcial) da oferta de moeda, o que conduz necessariamente à não aceitação da dicotomia clássica real versus monetário. É sobre estas premissas que uma abordagem que se proponha heterodoxa deve se pautar.

\section{REFERENCIAS}

ALVES, JR., A.; FERRARI-FILHO, F.; PAULA, L. F. R. The post Keynesian critique of conventional currency crisis models and Davidson's proposal to reform the international monetary system. Journal of Post Keynesian Economics, v. 22, n. 2, p. 209-227, Winter 1999-2000.

CARVALHO, F. C. A teoria monetária de Marx: uma interpretação póskeynesiana. Revista de Economia Politica, v. 6, n. 4, p. 5-21, out./dez. 1986. 1992.

Mr Keynes and the post keynesians. Cheltenham: Edward Elgar,

. Sobre a endogenia da oferta de moeda: réplica ao Professor Nogueira da Costa. Revista de Economia Política, v. 13, n. 3, p. 114-121, jul./set. 1993.

CHICK, V. The evolution of the banking system and the theory of saving, investment and interest. In: On money, method and Keynes: selected essays. London: MacMillan, 1992.

COSTA, F. N. (Im)propriedades da moeda. Revista de Economia Política, v. 13 n. 2, p. 61-75, abr./jun. 1993.

. Sobre o "horizontalismo" da oferta da moeda: tréplica ao Professor Cardim de Carvalho. Revista de Economia Política, v. 14, n. 1, p. 142-146, 1994.

DAVIDSON, P. International money of the real world. $2^{\text {nd }}$ Edition. London: Macmillan, 1992.

. Post Keynesian macroeconomics theory. Aldershot: Edward Elgar, 1994.

. Colocando as evidências em ordem: macroeconomia de Keynes versus velho e novo keynesianismo. In LIMA, G. T.; SICSÚ, J.; PAULA, L. F. (orgs.), Macroeconomia moderna: Keynes e a economia contemporânea. Rio de Janeiro: Campus, 1999.

DYMSKI, G.; POLLIN, R. Hyman Minsky as hedgehog: the power of the Wall Street Paradigm. In FAZZARI, S.; PAPADIMITRIOU, D. (eds.), Financial conditions and macroeconomic performance. Armonk/ London: M.E.Sharp, 1992. 
DOW, S. Horizontalism: a critique. Cambridge Journal of Economics, v. 20, p. 497-508, 1996.

FERRARI FILHO, F; CONCEIÇÃO, O. A noção de incerteza nos póskeynesianos e institucionalistas: uma conciliação possível? Anais do XXIX Encontro Nacional de Economia, 17p. Salvador: ANPEC, 2001.

FIOCCA, D. A oferta de moeda na macroeconomia keynesiana. São Paulo: Paz e Terra, 2000.

FRANKEL, J. No single currency regime is right for all countries or at all times. NBER Working Paper 7338. Washington: NBER, 1999.

FREITAS, C. P. Moeda endógena e passividade bancária: uma análise crítica da abordagem "horizontalista" e da teoria do circuito monetário. Revista de Economia Política, v. 19, n. 4, p. 114-133, 1999.

GERMER, C. "Economia monetária" ou "economia capitalista"? Marx e Keynes: sobre a natureza do capitalismo. Estudos Econômicos, v. 26, n. especial, p. 51-81, 1996.

GOODHART, C. Has Moore become too horizontal? Journal of Post Keynesian Economics, v. 12, n. 1, p. 29-34, Fall 1989.

KALDOR, $\mathrm{N}$. The scourge of monetarism. 2a. ed. Oxford: Oxford University Press, 1985.

KAUFMAN, G. Bank failures, systemic risk, and bank regulation. Working Papers Series WP-96-1. Chicago: Federal Reserve Bank of Chicago, January 1996.

KEYNES, J. M. The general theory of employment, interest, and money. New York: Harcourt Brace, 1964.

. The general theory and after, part I: preparation. Collected writings of John Maynard Keynes, vol. XIII. London: Macmillan, 1973a.

. The general theory of employment. In: The general theory and after: defence and development. Collected writings of John Maynard Keynes, vol. XIV. London: Macmillan, 1973b.

KLAGSBRUNN, V. H. A gênese do princípio da demanda efetiva. Estudos Econômicos, v. 26, n. especial, p. 135-163, 1996.

KREGEL, J. The past and future of banks. 1997. Mimeografado.

MEULENDYKE, A. Can the Federal Reserve influence whether the money supply is endogenous? A comment on Moore. Journal of Post Keynesian Economics v. 10, n. 3, p. 390-7, Spring 1988.

MINSKY, H. Can 'TT' happen again? Essays on instability and finance. New York: M. E. Sharpe, 1982. 1986.

. Stabilizing an unstable economy. New Haven: Yale University Press, 
MOLLO, M. L. R. A endogeneidade pós-keynesiana da moeda: traços ortodoxos e heterodoxos. Estudos Econômicos, v. 27, n. 3, p. 395-416, set./dez. 1997.

- A importância analítica da moeda em Marx e Keynes. Análise Econômica, ano 16, n. 29, p. 5-20, março 1998.

MOORE, B. The endogenous money supply. Journal of Post Keynesian Economics, v. 10 n. 3, p. 372-389, Spring 1988a.

. Horizontalists and verticalists: the macroeconomics of credit money. Cambridge: Cambridge University Press, 1988b.

. A simple model of bank intermediation. Journal of Post Keynesian Economics, v. 11, n. 1, p. 10-28, Fall 1989a.

. On the endogeneity of money once more. Journal of Post Keynesian Economics, v. 11, n. 3, p. 479-487, Spring 1989b.

PAULA, L. F. R. Liquidez e zeragem automática: crítica da crítica. Estudos Econômicos, v. 26, n. 3, p. 411-439, set./dez. 1996.

. Liquidez e "zeragem automática": uma tréplica a Ramalho. Estudos Econômicos, v. 27, n. 3, p. 527-530, set./dez. 1997.

. Dinâmica da firma bancária: uma abordagem não-convencional. Revista Brasileira de Economia, v. 53, n. 3, p. 136-142, jul./set. 1999.

PAULA, L. F. R.; ALVES JR., A. J. Comportamento dos bancos, percepção de risco e margem de segurança no ciclo minskiano. Análise Econômica, v. 21, n. 39, p. 135-162, março 2003.

POLLIN, R. Two theories of money supply endogeneity: some empirical evidence. Journal of Post Keynesian Economics, v. 13, n. 3, p. 397-403, Spring 1991.

POSSAS, M. Racionalidade e regularidades: rumo a uma integração micromacrodinâmica. Economia e Sociedade, n. 2, p. 59-80, agosto 1993.

RAMALHO, V. “Zeragem automática” no mercado aberto e controle monetário. Estudos Econômicos, v. 25, n. 1, p. 25-52, jan./abr. 1995.

. Liquidez e "zeragem automática": resposta. Estudos Econômicos, v. 27, n. 3, p. 519-525, set./dez. 1997a.

. Liquidez e "zeragem automática": nota final. Estudos Econômicos, v. 27, n. 3, p. 531-534, set./dez. 1997b.

SAAD-FILHO, A.; LAPAVITSAS, C. A teoria horizontalista da moeda e do crédito: uma análise crítica. Estudos Econômicos, v. 29, n. 1, p. 2345 , jan./mar. 1999.

SICSÚ, J. A negação da ineficácia da política monetária: uma alternativa de Keynes e dos pós-keynesianos. Análise Econômica, ano 15, n. 28, p. 80-107, 1997. 
TOBIN, J. The commercial banks as creators of "money". In: Essays in economics, v. l. Cambridge: MIT Press, 1987.

TORRES, M. J. R. Operacionalidade da politica monetária no Brasil. 1999. Tese (Doutorado). UNICAMP/IE, Campinas.

WRAY, L. Money and credit in capitalist economies: the endogenous money approach. Aldershot: Edward Elgar, 1990.

Agradeço as sugestôes feitas por Fernando Ferrari Filho e por um parecerista anônimo. Evidentemente, erros e omissões são de minha inteira responsabilidade. Este trabalho foi desenvolvido no âmbito do Grupo de Estudos da Moeda e Sistema Financeiro do Instituto de Economia da Universidade Federal do Rio de Janeiro (website: www.ie.ufrj.br/moeda).

E-mail: 11paula@alternex.com.br.

(Recebido em setembro de 2002. Aceito para publicação em janeiro de 2003). 